\title{
The relationship between Pacific SSTA and Autumn Extreme Precipitation Events of China
}

\author{
CHEN Jin-ming ${ }^{1,2}$, GU Shi-xiang ${ }^{1}$, JIANG Ru-cheng ${ }^{1}$, LU Gui-hua ${ }^{2}$, WU Zhi-yong ${ }^{2}$, DU Xuan-xuan ${ }^{1}$ \\ ${ }^{1}$ Yunnan Institute of Water \& Hydorpower Engineering Investigation, Design and Research, Kunming 650021, China; \\ ${ }^{2}$ College of Hydrology and Water Resource, Hohai University, Nanjing 210098, China,
}

\begin{abstract}
Based on 610 Meteorological stations daily precipitation datasets in China and NCEP/NCAR reanalysis datasets and NOAA reconstruct sea surface temperature from 1960 2009, the spatial and temporal coupling relationships between the Pacific SSTA and extreme precipitation events (EPE) are analyzed by using Singular Value of Decomposition method. Moreover, possible effect mechanism of Pacific SSTA for EPE is also discussed, the results are as follows: They are remarkable relations between equator middle-east Pacific ocean (EMEPO) SSTA and EPE. In anomaly cold years of EMEPO, compel $500 \mathrm{hPa}$ height field to show reverse PNA teleconnection pattern, intensity of west Pacific ocean subtropical high boost down. Meanwhile North Africa subtropical high become weeker compared with the mean. The trough over East Asia is abnormally weaker, and zonal circulation prevails over Asia, which is useful for the northward motion of southwestern water vapor. Meanwhile, the $500 \mathrm{hPa}$ geopotential height become weeker in New Siberian, leading to development and eastward motion of westerly trough. It is useful for the southward motion of stronger cold air, which is beneficial to the interaction between cold and warm air in Huang-Huai Basin, benefit the occurrence of EPE. However, wester china influenced by western vapor transportation, and vapor divergence in these areas, not benefit the occurrence of EPE. The opposite is true with positive SSTA in EMEPO.
\end{abstract}

\section{Introduction}

The main effect of the oceans in the atmosphere is to provide heat and moisture to the atmosphere, and provide energy for atmospheric movement. The ocean, which accounts for $70.8 \%$ of the Earth's surface area, provides about $70 \%$ of the energy source and $85 \%$ of the water vapor source for the atmosphere through long-wave radiation, latent heat of vaporization, turbulent sensible heat, and evaporation. Therefore, the anomaly of the sea surface temperature will cause anomalies in the atmospheric circulation, and the anomalies of the atmospheric circulation will lead to abnormal weather and climate, and thus cause abnormal precipitation. ENSO is a typical representative. China's continental monsoon climate is significant. One of the main driving forces of monsoon formation is the difference between sea and land heat. The sea temperature anomaly will affect the precipitation in China by affecting the strength of the East Asian monsoon and China's water vapor transport. Therefore, studying the relationship between sea surface temperature anomalies and extreme precipitation events in China is of great significance for further research on the causes of precipitation anomalies in China and disaster prevention and mitigation.

In recent years, there have been many studies on the relationship between sea surface temperature anomalies and precipitation in China ${ }^{[1-5]}$ and extreme precipitation events ${ }^{[6-9]}$. Studies have shown that the sea surface temperature anomalies in the Equatorial East Pacific, the Western Pacific Warm Pool, the Indian Ocean, the Arabian Sea, the Kuroshio area and other sea areas are closely related to precipitation anomalies in China. However, these studies are mainly to explore the relationship of the sea surface temperature anomaly and the summer precipitation and extreme daily precipitation events (the daily precipitation is frequency-distributed, if the precipitation exceeds a certain percentage threshold on a certain day, it is defined as an extreme precipitation event) in China, and there are few studies on sea surface temperature anomalies and other seasonal extreme precipitation events and long-term heavy precipitation events, which is defective. First of all, extreme daily precipitation is a short-duration and high-intensity torrential rain. However, in addition to short-duration and high-intensity torrential rains, precipitation caused by floods has a long-lasting (continuous multi-day) heavy precipitation process. Long-term heavy precipitation often causes natural disasters such as floods, mudslides and landslides. Therefore, while paying attention to extreme daily precipitation, we should pay more attention to the study of the long-term precipitation process. Zou Yongchang et al. [10] defined the precipitation that lasted for two days and above on a rainy day as the precipitation process, and defined the extreme precipitation events to avoid the situation that 
the cross-border extreme precipitation events could not be identified and the existing extreme precipitation. The study is a good complement to the lack of attention to continuous precipitation. Secondly, ENSO caused by sea surface temperature anomaly is the most recognized signal of interannual climate anomaly, which has a great impact on precipitation anomalies in China. Previous studies have shown that the relationship between ENSO and precipitation anomalies in autumn is even more obvious in summer ${ }^{[11,12]}$. However, there are still very few studies on the relationship between extreme precipitation events and sea temperature in autumn in China.

Therefore, this paper takes the extreme precipitation events of the Pacific sea surface temperature and the autumn long duration (continuous multi-day) as the research object, and uses the singular value decomposition (SVD) method to study the coupling relationship between the Pacific sea surface temperature anomalies and the extreme precipitation events in autumn in China, and analyzes the sea surface temperature anomalies. The anomalous characteristics of circulation in the year to explore the possible mechanism of sea surface temperature anomalies affecting extreme precipitation events in autumn in China.

\section{Materials and Methods}

\subsection{Materials}

(1) The data used are the daily precipitation data of 756 stations in China from 1960 to 2009 compiled by the National Climate Center (China Meteorological Science Data Sharing Service Network, http://cdc.cma.gov.cn/). In order to avoid errors in the research results caused by data shortage, the selection of meteorological stations adopts stricter standards: 1 . The length of the data series is not less than 45 years (there are fewer stations in the western region, and the station is built later, the selection is not less than 40) The station of the sequence of more than one year); 2 . The number of days of missing data per year does not exceed 30 days. After the above two steps, a total of 610 sites were selected.

(2) Sea surface temperature data comes from the US National Oceanic and Atmospheric Administration (NOAA) for extended reconstructed monthly average sea surface data from January 1854 to December $2011^{[13]}$, the data resolution is $2^{\circ} \times 2^{\circ}$, a total of $180 \times 89$ grids. The length of the sea surface temperature sequence used in this paper is from January 1959 to December 2009.

\subsection{Research methods}

(1) Extreme precipitation events

Extreme precipitation events: all samples of precipitation in each stage of precipitation from 1960 to 2009 are arranged in ascending order, and the 90th percentile value of the sample is defined as the discriminant threshold of extreme precipitation events. In a precipitation process, a station has the amount of precipitation exceeds the threshold of this station, it is called an extreme precipitation event. For the definition of precipitation process, refer to the definition method of Zou Yongchang ${ }^{[10]}$, that is, from the beginning of rainy days $(\geqslant 0.1 \mathrm{~mm})$ to the interruption of rainy days. If the rainy days last for two days and more, define it as a precipitation process. The amount of precipitation per day during the precipitation process will increase the amount of precipitation during the precipitation process.

(2) Singular value decomposition

The Singular Value of Decomposition (SVD) [14] introduced by matrix theory becomes an important diagnostic tool for studying the relationship between two meteorological elements. It can be used to analyze the spatial structure of the correlation coefficient field between two fields and their respective contributions to the correlation field, which is difficult to do with point correlations such as the simple Person correlation coefficients. SVD decomposition not only has a solid mathematical foundation, but also is simple and easy to perform physical interpretation. It is more efficient than typical correlation analysis (CCA) and joint principal component analysis (CPCA), especially for the correlation analysis of large-scale feature fields. It is widely used in meteorological, climate diagnostic analysis and prediction ${ }^{[15,16]}$. The principle of SVD is as follows:

There are two fields, $\mathrm{X}$ and $\mathrm{Y}$, which are called left and right fields respectively. The left field has $\mathrm{p}$ spatial points (or variable numbers), $\mathrm{N}$ observations, and the right field has q spatial points (which can be different from $\mathrm{p}$ ) and also $\mathrm{N}$ observations. Two orthogonal linear transformation matrices $\mathrm{L}$ and $\mathrm{R}$ can be found by decomposing SVD, and then

$$
A_{p \times q}=X Y^{T}=L_{p \times m} \Lambda_{m \times m} R_{m \times q}^{T}
$$

Since $\mathrm{L}$ and $\mathrm{R}$ are orthogonal, the left $(\mathrm{Um} \times \mathrm{N})$ right $(\mathrm{Um} \times \mathrm{N})$ time coefficient can be expressed as:

$$
U_{m \times N}=L_{p \times m}^{T} X_{p \times N} \quad V_{m \times N}=R_{q \times m}^{T} Y_{q \times N}
$$

The time coefficient is arranged from the largest to the smallest in terms of the covariance of the pair. Therefore, the relationship between the first $n$ pairs of time coefficients largely represents the coupling relationship between the two element fields, so that the correlation of two fields of $p$ and $q$ is greatly simplified and the focus is highlighted. Each pair of time coefficients determines a modality, and the coefficient of heterosexual correlation indicates the overall influence of a certain modal time change of one field on another. Its significant correlation area is the area of the most critical of the other field affected by this modality, and the formula is as follows:

$$
r_{k}(X, V)=\frac{E\left[x_{i}(t) V_{k}(t)\right]}{E\left(x_{i}^{2}(t)\right)^{1 / 2} E\left(V_{k}^{2}(t)\right)^{1 / 2}} \quad r_{k}(Y, U)=\frac{E\left[y_{i}(t) U_{k}(t)\right]}{E\left(y_{i}^{2}(t)\right)^{1 / 2} E\left(U_{k}^{2}(t)\right)^{1 / 2}}
$$

The correlation coefficient $\mathrm{r}_{\mathrm{k}}(U, V)$ between the $\mathrm{k}_{\mathrm{th}}$ pair of time coefficients represents the closeness (i.e., the degree of remote coupling) of the spatial distribution of the left and right fields of the coupled mode, and the calculation formula is as follows: 


$$
r_{k}(V, U)=\frac{E\left[V_{k}(t) U_{k}(t)\right]}{E\left(V_{k}^{2}(t)\right)^{1 / 2} E\left(U_{k}^{2}(t)\right)^{1 / 2}}
$$

\section{Selection of key areas of sea temperature}

For a total of 50 years from 1960 to 2009, the frequency of autumn extreme precipitation events at 610 stations in China is averaged nationwide to obtain a regional average sequence, then the point correlation coefficient between the sequence and the sea surface temperature of the Pacific Ocean $\left(20^{\circ} \mathrm{S} \sim 60^{\circ} \mathrm{N}, 120^{\circ}\right.$ $\mathrm{E} \sim 280^{\circ} \mathrm{E}$ ) (previous year) and the same period can be obtained, which is the frequency of extreme precipitation events in the fall and the Pacific Ocean temperature of the winter in the previous year, the spring in the same year, the summer in the same year and the fall in the same year.

The spatial distribution of the correlation coefficient
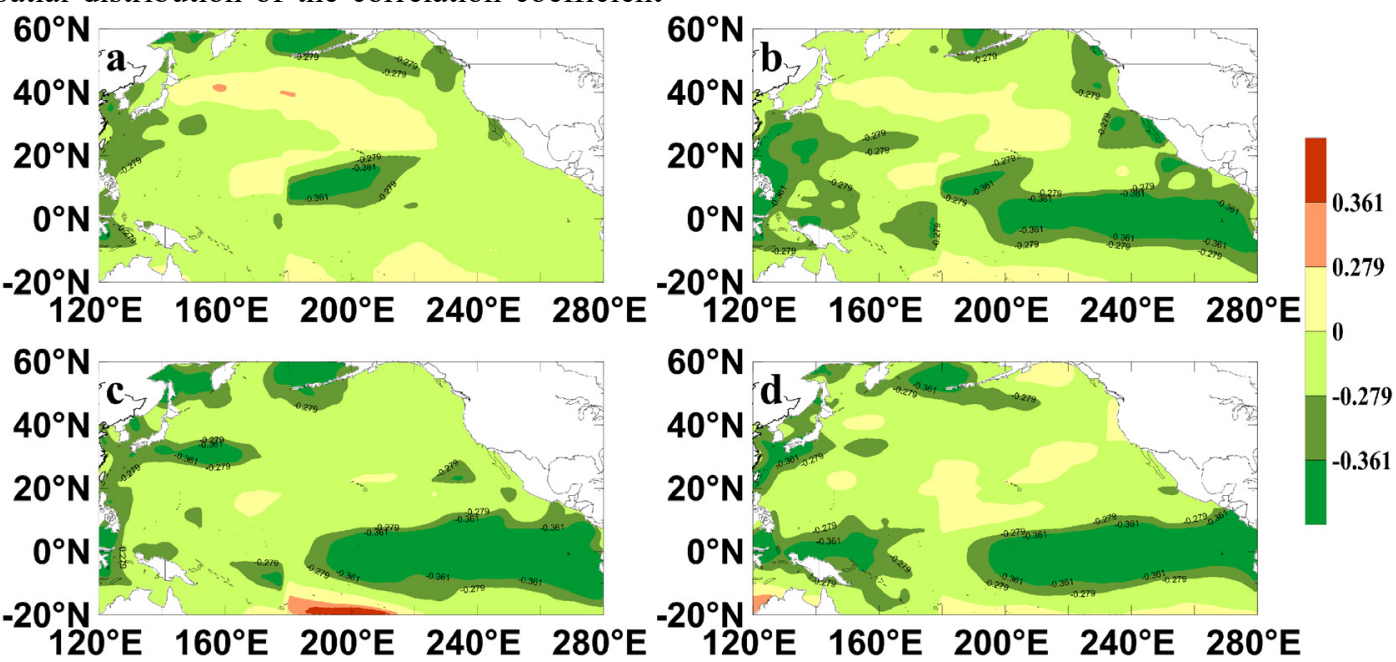

Figure 1. The distribution of corraltion cofficiences between autumn extreme precipitation events and (a) last winter, (b) spring, (c) summer, (d) autumm Pacific SSTA

\section{Coupling relationship between extreme precipitation events and sea surface temperature in the central equator and eastern Pacific}

Many studies ${ }^{[17,18]}$ have shown that the effect of sea surface temperature on precipitation anomalies in China has both synchronous effects and delayed effects, and they also have the most sensitive areas. Then, what is the relationship between the Pacific sea early stage temperature and the extreme precipitation events in autumn in China, and in which areas are the most sensitive areas? To solve this problem, the sea surface temperature anomalies in the key sea areas are set as left-field (time series length is 1959/1960-2008/2009), and the frequencies of extreme precipitation events in China's autumn (from September to November) are set as right field (time series length is 1960 2009). The standardized frequency field of autumn extreme precipitation events is performed time-delay coupled SVD decomposition with the standardized sea surface between the extreme precipitation event and the previous sea surface temperature is shown in Figure 1. It can be seen from the figure that the sea area in the central equator and eastern Pacific $\left(20^{\circ} \mathrm{S} \sim 20^{\circ} \mathrm{N}, 180^{\circ} \mathrm{E} \sim 280^{\circ} \mathrm{E}\right)$ is worthy of attention. This areas from the previous winter to the autumn in the same year were relatively stable, and the correlation coefficient can be below -0.279 , which is tested by the 0.05 significant level; while the rest of the sea areas such as the Kuroshio area, the tidal zone, and the west coast of North America were also significantly correlated, but there is no stability in the relevant areas. Considering the factors of correlation coefficient, stability of relevant regions and predictability of extreme precipitation, the central equator and eastern Pacific is selected as the key area with high correlation coefficient and stable regional stability. The following section will analyze the key areas of sea temperature and autumn extremes. The coupling relationship of precipitation events. temperature field of the former winter (average value from December to February, scheme 1), the former spring (average value of from March to May, scheme 2), and the former summer (average value from June to August, scheme 3) and the fall (average value from September to November, scheme 4).

The square covariance contribution rate and modal correlation coefficient of the first two pairs modes of the four coupling schemes are shown in Table 1. The optimal coupling scheme is selected based on the high modal correlation coefficient and the square covariance contribution rate. By comparison, it can be found that the extreme precipitation events in autumn in China are relatively significant in comparison with the sea surface temperature in the Middle East during the same period (scheme 4). The contribution rate of the first two pairs of modal cumulative square covariance is as high as $81 \%$, and the modal correlation coefficients are all greater than 0.84. It is indicated that the anomaly of the sea surface temperature in the central equator and eastern Pacific during the same period has a clear indication of the extreme precipitation events in autumn China. At the 
same time, as can be seen in the Table 1, the contribution rate of the square covariance of the first pair of modes is as high as $71.5 \%$, which indicates that the mode contains most of the information of the left and right field coupling relationship; the correlation coefficient of the mode is also as high as 0.87 , which has passed a significance level test of 0.001 , indicating that the

Table 1. The percentage of the squared covariance expl correlation between the modes was significant. Therefore the following is mainly to analyze the spatial distribution characteristics of the first mode of the isotropic correlation coefficient of the scheme 4 to explore the coupling relationship between the sea temperature in the equatorial middle east Pacific and the extreme precipitation events in autumn in China.

\begin{tabular}{ccccccccc}
\hline & \multicolumn{3}{c}{ Scheme 1 } & & Scheme 2 & & Scheme 3 & \multicolumn{2}{c}{ Scheme 4 } \\
\cline { 2 - 10 } Modal & $\begin{array}{c}\text { Correlation } \\
\text { coefficient }\end{array}$ & $\begin{array}{c}\text { Square } \\
\text { covariance } \\
\text { contributio } \\
\text { n rate }\end{array}$ & $\begin{array}{c}\text { Correlation } \\
\text { coefficient }\end{array}$ & $\begin{array}{c}\text { Square } \\
\text { covariance } \\
\text { contributio } \\
\text { n rate }\end{array}$ & $\begin{array}{c}\text { Correlation } \\
\text { coefficient }\end{array}$ & $\begin{array}{c}\text { Square } \\
\text { covariance } \\
\text { contributio } \\
\text { n rate }\end{array}$ & $\begin{array}{c}\text { Correlation } \\
\text { coefficient }\end{array}$ & $\begin{array}{c}\text { Square } \\
\text { covariance } \\
\text { contributio } \\
\text { n rate }\end{array}$ \\
\hline 1 & 0.88 & 54.7 & 0.83 & 51.3 & 0.86 & 60.3 & 0.87 & 71.5 \\
2 & 0.89 & 12.7 & 0.88 & 16.3 & 0.84 & 14.1 & 0.84 & 9.5
\end{tabular}

Figure 2 shows the change of the spatial distribution and time coefficient of the first model-specific correlation coefficient between the extreme precipitation events in autumn China and the first model-specific correlation coefficient of SVD in the central equator and eastern Pacific Ocean during the same period. It can be seen from Figure $2 \mathrm{a}$ that the entire central equator and eastern Pacific field has a positive distribution during the same period of autumn, and the correlation coefficient is very high (larger than 0.6 ). The most significant positive anomaly is located in the area from New Guinea to the Socirty Islands, and the correlation coefficient is larger than 0.8. The distribution of the isotropic correlation coefficient of the extreme precipitation process is relatively complicated (Fig. 2b). The area around the west of $90^{\circ} \mathrm{E}$ (hereinafter referred to as the west), the southwest and the middle and lower reaches of the Yangtze River has a positive value distribution; east of $90^{\circ} \mathrm{E}$, north of $30^{\circ} \mathrm{N}$ (hereinafter referred to as the North) and the coastal areas in the south of China are negative value. The most significant negative correlations are located in the Yellow River Basin and the southern part of the Huaihe river basin, with a correlation coefficient of less than -0.3. It can be seen from the time coefficients in the two field (Fig. 2c) that the left and right field changes are very consistent, and the modal correlation coefficient reaches 0.87 , which indicates that when the sea temperature in the central equator and eastern Pacific Ocean is abnormally warm (cold) during the same period, most of northern China extreme precipitation events in the coastal areas of South China and the coastal areas of South China are relatively small (large), while most of the areas in the west, southwest and the middle and lower reaches of the Yangtze River are abnormally high (less), which is accordance with the conclusions of studying Chen Yun ${ }^{[12]}$ and Li Yaohui ${ }^{[19]}$ the relationship between abnormal precipitation in autumn and ENSO in China. Since the most significant relevant area is located in the Huanghuai River Basin, it indicates that the extreme precipitation events in the Huanghuai River Basin in China are most sensitive to the anomaly of the sea surface temperature in the autumn and the equatorial Middle East.

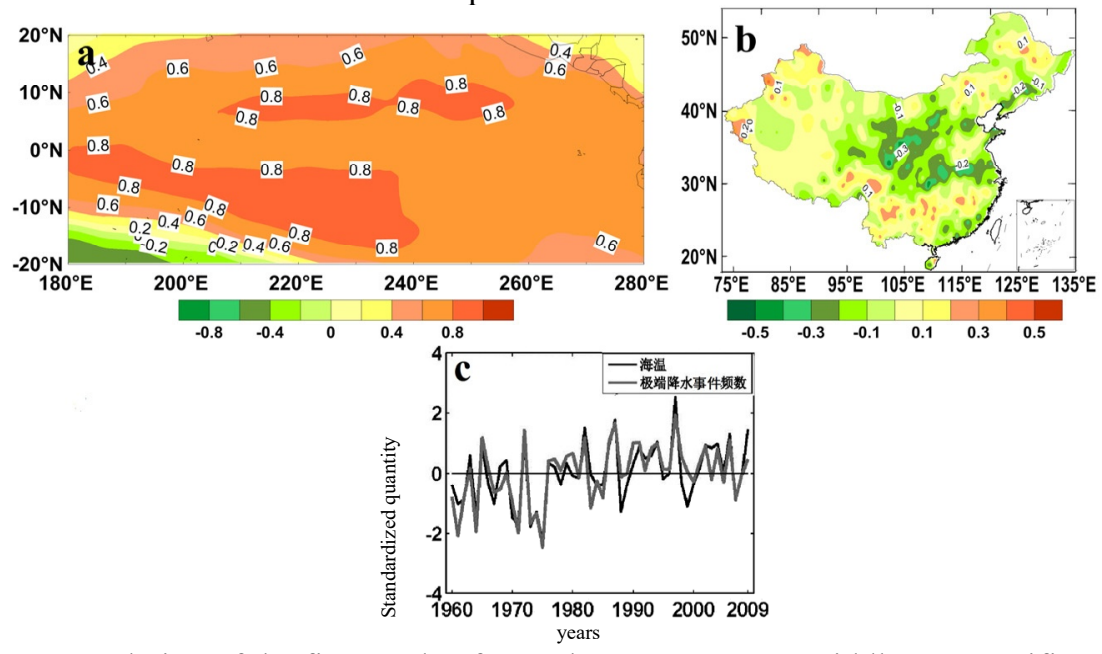

Figure 2. The hetero-correlation of the first mode of SVD between equator middle-east Pacific ocean SSTA (a) and extreme precipitation events (b) and standardization time coefficients (c) 


\section{Possible Mechanisms of Extreme Precipitation Events Affecting Sea Surface Temperature in the Equatorial Middle East and Pacific Ocean}

Through the extreme precipitation event field and the SVD decomposition of the key sea surface SVD, the first mode can be known. During the same period, the central equator Pacific sea temperature in the autumn is closely related to the extreme precipitation events in the Yellow River and Huaihe River Basin in China. How does the key sea surface temperature affect the extreme precipitation in China? What about the event? As we all know, the influence of sea surface temperature on precipitation is mainly achieved by changing the atmospheric circulation situation. For this reason, synthetic analysis method is used to compare the anomalous characteristics of atmospheric circulation in the anomalous year of sea temperature to find the possibility of sea temperature anomaly affecting the extreme precipitation events in autumn in China. mechanism. The World Meteorological Organization (WMO) refers to the event that the meteorological element sequence anomaly reaches 1.3 times of the standard deviation $(1.3 \sigma)$ and 2 times of the event of the standard deviation $(2 \sigma)$ as abnormal events and serious events ${ }^{[20]}$. According to the provisions of WMO, the year of the sea temperature sequence $\pm 1.3 \sigma$ is selected as the cold and warm year of sea surface temperature.

The first modal time coefficient of the left field (sea temperature field) of the optimal coupling scheme is

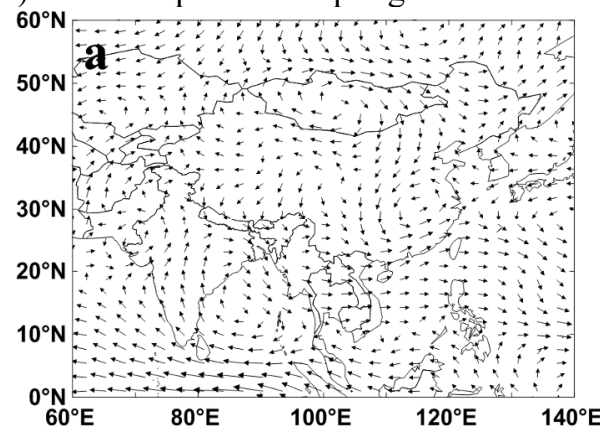

Figure 3. $850 \mathrm{hPa}$ wind anomaly fields in warm (a) and cold (b) years of SSTA anomaly of equator middle-east Pacific ocean in autumn

\section{$5.2500 \mathrm{hPa}$ height field anomaly}

Many studies by predecessors have shown that ${ }^{[21-24]}$, the subtropical high has an important impact on precipitation in China, so how does the sea temperature in the central equator and eastern Pacific affect the extreme precipitation in autumn in China through the bridge of $500 \mathrm{hPa}$ height field? To this question, the difference of the $500 \mathrm{hPa}$ height field of the sea surface temperature anomaly year is compared. The anomalous cold and warm year $500 \mathrm{hPa}$ anomaly field is shown in Figure 4. It can be seen from Figure 4a that the Antarctic middle east pacific ocean temperature is abnormally warm, and the $500 \mathrm{hPa}$ height anomaly field in the same autumn shows a more obvious PNA type ${ }^{[7]}$, that is, the tropical and subtropical Pacific and the northwestern part of North

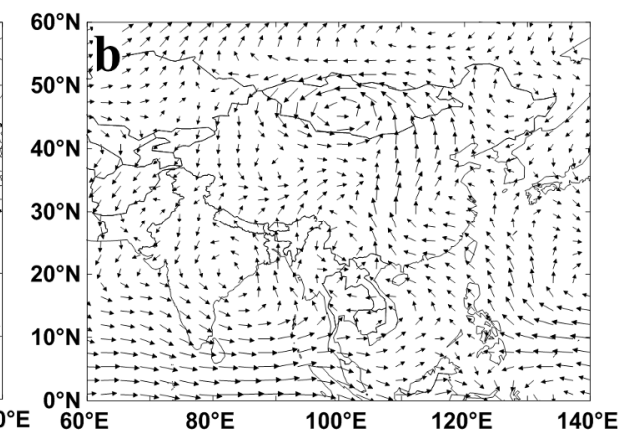

standardized, and the $\pm 1.3 \sigma$ year is selected as the abnormal cold and warm year. After screening, the abnormal warm years are 1982, 1987, 1997, 2006, 2009. The abnormal cold years were 1964, 1970, 1971, 1973, and 1975.

\section{1 $850 \mathrm{hPa}$ wind field anomaly}

Figure $3 \mathrm{a}$ and $\mathrm{b}$ are the anomalous warm and cold $850 \mathrm{hPa}$ anomalous wind field in the same period of autumn. It can be seen from Figure $3 \mathrm{a}$ that the abnormal warm year, Eastern north China and Huanghuai river basin are prevailing in the northerly airflow, indicating that the dry and cold air in this area is relatively strong, which results in this area to be dry and cold, and there are abnormal cyclones in the middle and lower reaches of the Yangtze River. The convergence of the bottom layer is conducive to precipitation. This circulation situation leads to less extreme precipitation events in the Yellow River Basin, and more in the middle and lower reaches of the Yangtze River. The eastward airflow prevails in the west part, which is conducive to the occurrence of extreme precipitation events. The abnormal cold years are just the opposite of the abnormal warm years (Fig. 3b). The Huanghuai River Basin prevails in an abnormally southerly airflow, indicating that the warm and humid airflow is relatively strong, which is conducive to precipitation, and results in more extreme precipitation events in the Huanghuai river basin; The water vapor is dry and cold, so the extreme precipitation is less.

America are positive value, Aliu Shen and the eastern part of the United States are negative value. When the central equator and eastern Pacific Ocean is abnormally cold (Fig. 4b), the $500 \mathrm{hPa}$ height anomaly field in the same autumn is quasi-anti-PNA type ${ }^{[7]}$, and the spatial distribution is consistent with the abnormal warm year, but the positive and negative signs are just the opposite.

It can be seen from the above analysis that the abnormal warming of the sea surface temperature in the central equator and eastern Pacific during the same period will lead to the PNA-type teleconnection of the $500 \mathrm{hPa}$ height anomaly in the same year, which will cause the western Pacific subtropical high to be higher than normal, and vice versa. In the following, we compare the difference of the $500 \mathrm{hPa}$ height synthesis field in the abnormal cold and warm years to explore the impact of the western Pacific subtropical high on the 
extreme precipitation events in autumn in China.
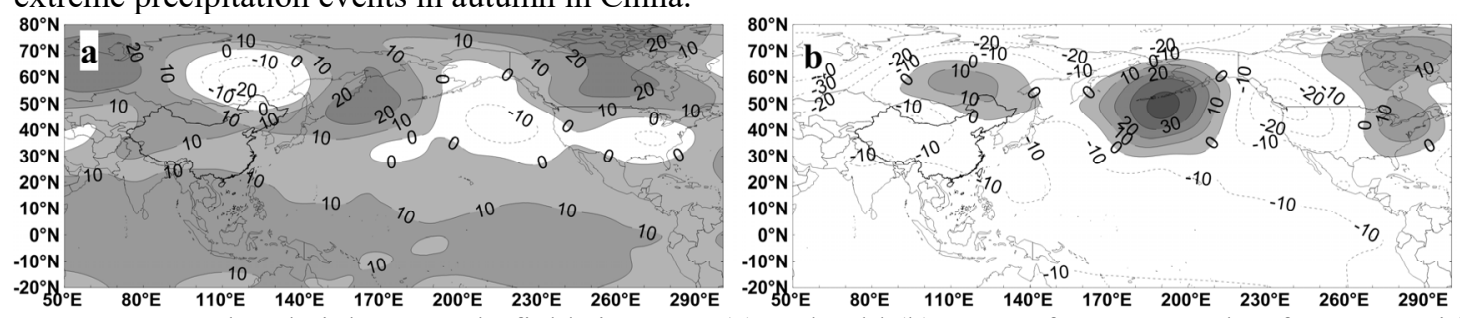

Figure 4. $500 \mathrm{hPa}$ height anomaly fields in warm (a) and cold (b) years of SST anomaly of equator middle-east Pacific Ocean in autumn

Figure 5a, b, and c show the asymmetry cold and warm annual $500 \mathrm{hPa}$ synthetic height field in the central equator and eastern Pacific Ocean and the $500 \mathrm{hPa}$ synthetic height field from 1960 to 2009, respectively. Table 2 shows the mean cold and warm annual circulation index averaged percentage (from the 74 circulation index of the national climate center).

During the autumn, when the sea surface temperature in the central equator and eastern Pacific Ocean was abnormally warm, the western subtropical high was obviously stronger in the autumn $(33 \%$, see in Table 2 , omitted below), and the position was southward and westward, and the 5860 geopotential meter line westly extends to $90^{\circ} \mathrm{E}$ (Fig. 5a), the middle and lower reaches of the Yangtze River are located in the rainfall zone where the cold and warm water flows near the north side of the subtropical high, and there are more extreme precipitation events; South China is located in the subtropical high (within the 5860 line), and the submerged airflow prevails, and the extreme precipitation events are less; The Huanghuai River Basin is far away from the rainy and warm waters of the north side of the subtropical high, resulting in significantly less extreme precipitation events in the area. In the abnormal cold years, the west subtropical high is abnormally weak, eastward and northerward (5\%), and the Asian zonal circulation index is as strong as $19 \%$. The East Asian trough is significantly weaker, and the North African

\begin{tabular}{ccc} 
Table 2. Circulation index Anomaly in warm (a) and cold (b) year of SSTA anomaly (unit, \%) \\
\hline circulation index & asymmetry warm & asymmetry cold \\
\hline the north african high area intensity index & 32.7 & -24.6 \\
the high ridge line of north Africa & -0.1 & 24.0 \\
North Africa & 0.6 & 19.6 \\
Western Pacific high strength Index & 28.4 & -1.1 \\
The western Pacific ridge line & -8.1 & 0.2 \\
North west Pacific & -5.2 & 4.0 \\
Asian latitude index & -11.1 & 12.0 \\
Asian longitude index & -1.4 & 18.2 \\
East Asia slot & 6.1 & -10.4 \\
East Asia groove strength & -1.6 & 0.7 \\
\hline
\end{tabular}

high pressure is weaker as $27 \%$, which is greatly conducive to the southwest warm and humid air flow to the north of China, while the height of Novosibirsk is low (Fig. 5b), which is beneficial to the eastward movement and deepening of the west wind trough, which is conducive to the cold air from the back of the trough to the south. The intersection of cold and warm water flows led to more extreme precipitation events in the Huanghuai river basin. This is consistent with the results of previous studies. Jia Xiaolong et al. ${ }^{[25]}$ also pointed out that the characteristics of autumn precipitation in China in 2007 are closely related to the La Nina event (the equatorial eastern Pacific to $180^{\circ} \mathrm{E}$ sea surface temperature is cold). During the La Nina event. The high altitude of Lake Baikal and the development of the low trough of Lake Balkhash-Baikal and the northerly subtropical high make the cold air active in the northern part of China. At the same time, the southwest monsoon and the India-Myanmar trough are stronger and deeper than normal, resulting in abnormally high The warm and humid water vapor is transported from the South China Sea and the Bay of Bengal to the northern part of China. The high-latitude cold airflow and the low-latitude heating flow meet in the northern part of China, and there is a strong anomalous water vapor convergence, resulting in the precipitation distribution characteristics of less in the south and more in the north in autumn and winter in China. 


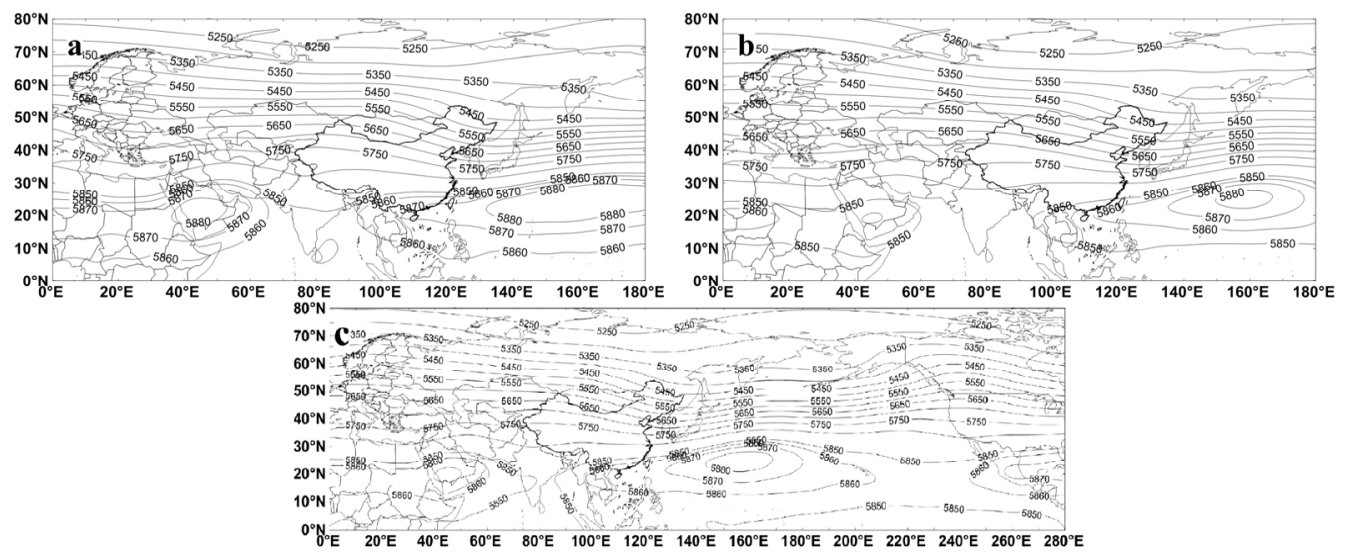

Figure 5. Composition of $500 \mathrm{hPa}$ height fileds of autumn of warm (a), cold (b) years and 1960 2009 (c) of SSTA anomaly of equator middle-east Pacific ocean

\subsection{The whole layer of water vapor transport flux and water vapor flux divergence is abnormal}

In order to further understand the influence mechanism of sea surface temperature anomalies in key sea areas on extreme precipitation events in China, the anomalous cold and warm water flow flux anomaly field and water vapor flux divergence anomaly field are shown in Figure 6. It can be seen from Figure 6a that the northeast of the abnormal warm year is mainly the northwest water vapor transport, the mid-latitude is the abnormal Dongfeng water vapor transport; the south is the abnormal southwest water vapor transport from the Bay of Bengal. The water vapor convergence is mainly distributed in the south of $30^{\circ} \mathrm{N}$ in China and the western part of China, resulting in more extreme precipitation events in these

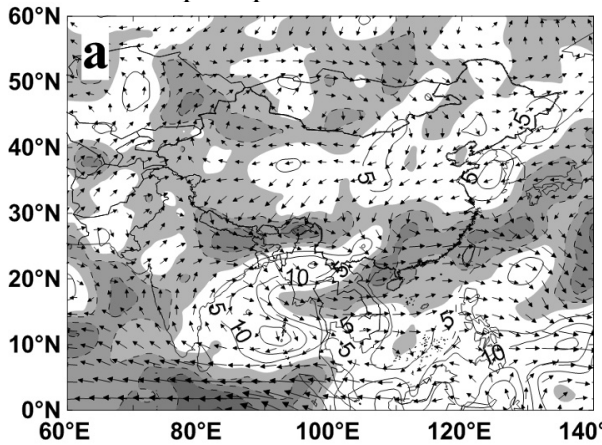

areas. The water vapor in other areas is abnormally divergent and the extreme precipitation events are less. In the abnormal cold years (Fig. 6b), the abnormal warm and humid water vapor from the Bengal Bay and the western Pacific is transported from the south China to the northwest, and merges with the west wind and water in the northwest and the Yellow River, and eastward to the northeast of China; In the west, there is consistent westerly water vapor transport. The anomalous convergence of water vapor in the coastal areas of South China and the north of the Yangtze River has caused extreme precipitation events in this area. And the water vapor in the west, southwest and middle and lower reaches of the Yangtze River is abnormally divergent, and there are few extreme precipitation events.

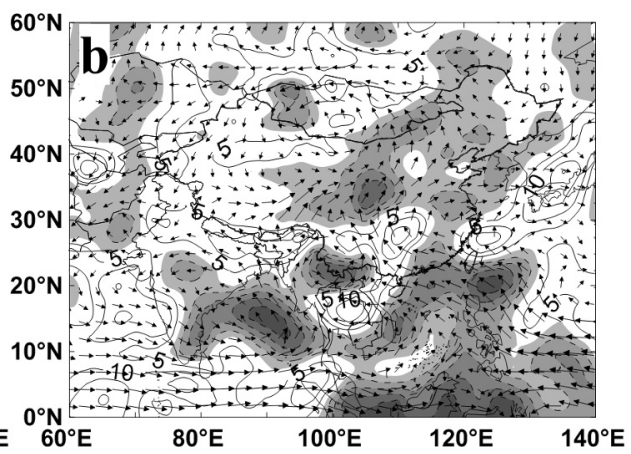

Figure 6. The same as Fig.3, but for the integrated moisture flux (the vector, units: $\mathrm{kg} \cdot \mathrm{m}^{-1} \cdot \mathrm{s}^{-1}$ ) and its divergence (the contour, units: $\left.10^{-5} \mathrm{~kg} /\left(\mathrm{m}^{2} \cdot \mathrm{s}\right)\right)$

\section{Conclusion}

The SVD method is used to study the time-delay coupling relationship between the Pacific sea surface temperature and the autumn extreme precipitation events, and the key sea areas affecting the extreme precipitation events in autumn in China are determined. The influence of sea surface temperature anomalies is analyzed by analyzing the anomalous characteristics of atmospheric circulation in the sea surface temperature anomaly years. The possible mechanism of my extreme precipitation event in autumn mainly came to the following conclusions:

(1) The change of sea surface temperature in the Pacific Ocean is significantly correlated with the change of extreme precipitation events in autumn in China.
During the same period, the central equator and eastern Pacific Ocean $\left(20^{\circ} \mathrm{S} \sim 20^{\circ} \mathrm{N}, 180^{\circ} \mathrm{E} \sim 280^{\circ} \mathrm{E}\right)$ is the key area affecting the extreme precipitation events in autumn in China. When the sea temperature in the key area is abnormally cold (warm), extreme precipitation events in the most area of north-eastern part of China (In the east of $90^{\circ} \mathrm{E}$, north of $30^{\circ} \mathrm{N}$ ) and coastal areas in South China are less (more), while most of the areas in the west of China (west of $90^{\circ} \mathrm{E}$ ), southwest, and the middle and lower reaches of the Yangtze River are abnormally more (less).

(2) In the autumn, the sea surface temperature in the central equator and eastern Pacific Ocean is abnormally colder. The $500 \mathrm{hPa}$ height anomaly field in the same period is anti-PNA type, the western Pacific subtropical high is obviously weaker, northerly and eastward, and the 
Asian zonal circulation index is stronger. The East Asian trough is significantly weaker, and the North African high pressure is weaker and northerly, which greatly facilitates the southwest warm and humid airflow to the north of China. At the same time, the Novosibirsk height field is low, causing the westerly trough to move eastward and deepen, which is beneficial to the cold air from behind the trough. The south part of the south is active over Huanghuai, and the intersection of cold and warm airflow leads to more extreme precipitation events in the Huanghuai river basin. In the abnormal warm year, the $500 \mathrm{hPa}$ height anomaly field is PNA type, the west subtropical high is obviously stronger, southerly and westward, and the middle and lower reaches of the Yangtze River are located in the rain zone where the cold and warm water flows in the north side of the subtropical high, and there are more extreme precipitation events; South China is under high pressure control, and the downdraft airflow is prevailing. The extreme precipitation events are less; the Huanghuai River Basin is not in the intersection of the cold and warm waters on the north side of the subtropical high, resulting in a significant decrease in extreme precipitation events in this area.

(3) In the autumn of the equatorial Middle East and the Pacific Ocean, the northeastern part of the Yangtze River in the east of China has a warm southwest warm and humid airflow from the Bay of Bengal. The southeast coast of China has a warm southeast warm and humid airflow, and the water vapor is abnormally converged, resulting in more extreme precipitation events in these two regions. In the west, it is consistent with the westerly water vapor transport, the water vapor is dry and cold and the water vapor is abnormally divergent, so the extreme precipitation events are less. Abnormal warm years, the south is anomalous southwest water vapor transport, water vapor anomaly convergence, north is northerly water vapor transport, water vapor is abnormally divergent, east winds are prevailing in the west, water vapor is abnormally convergent, causing more extreme precipitation events in the south and west of China, but less in the north.

\section{Acknowledgment}

The study is financially supported by the Key Program of Yunnan Applied Basic Research Projects (No. 2017FA022 ), the Academician Workstation Project (No. 2015IC013) and Scientific Research and Technical Innovation Team Construction of Yunnan Province (No. 2017TD025).

\section{References}

1. JIAN Maoqiu, LUO Huibang, QIAO Yunting. Linkage between the interannual Variation Patterns of Seansonal SST in Indian Ocean-Pacific and their Relationship with the summer rainfall over China [J]. Journal of Tropical Meteorology, 22(02): 131-137 (2006)

2. ZHANG Tianyun, SUN Zhaobo, LI Zhongxian, et al. Relation between Spring KUROSHIO SSTA and Summer Rainfall in China [J]. Journal of Tropical Meteorology, 23(02): 189-195.(2007)

3. WU Shengan, JIANG Zhihong, LIU Zhixiong, et al. Study on the correlations between decadal variability of Pacific SSTA and that of Rainfall in China [J]. Journal of Tropical Meteorology, 21(02): 153-162(2005)

4. ZHANG Qilong, WENG Xuechuan, Cheng Minghua. Relationship between the Precipitation in the rainy season in North China and the Tropical western Pacific warm pool and KUROSHIO [J]. PLATEAU METEORLOGY, 18(04): 575-583(1999)

5. ZHAO Yongjing, QIAN Yongfu. Analyses of Impacts of Global SSTA on Precipitation Anomaly in China [J]. Journal of Tropical Meteorology, 25(05): 561-570 (2009)

6. HUANG Maodong, LIAO Shixiang, ZHANG Chenhui. Analysis of the Mechanism of Pacific SSTA Influencing extreme Rainfall Precipitation events in annually first Raining season in Guangdong [J]. Journal of Tropical Meteorology, 25(04): 413-420 (2009)

7. YANG Jinhu, JIANG Zhihong, WANG Pengxiang, et al. Relation research on between SSTA of Pacfic and extreme precipitation events in the western China [J]. ACTA Oceanologica Sinica, 32(01): 23-33(2010)

8. JIANG Zhihong, YANG Jinhu, ZHANG Qiang. Influence study on Spring Indian Ocean SSTA to Summer extreme Precipitation events over the eastern Part of Northwest China [J]. Journal of Tropical Meteorology, 25(06): 641-648(2009)

9. ZHANG Yongling, DING Yuguo. The Teleconnection between Summer Extreme Precipitation over East China and North Pacific SSTA [J]. Journal of Nanjing Institute of Meteorology, 27(02): 244-252(2004)

10. ZOU Yongchang, YANG Xiuqun, SUN Xuguang, et al. Seasonal difference of the spatio-temporal variation of the number of the extreme precipitation processes in China $[\mathrm{J}]$. Journal of Nanjing University (Natural Sciences), 45(01): 98-109 (2009)

11. GONG Daoyi, WANG Shaowu. Impact of ENSO on the seasonal Rainfall in China $[\mathrm{J}]$. Journal of Natural Disasters, , 7(04): 44-52. (1998)

12. CHEN Yun, SHI Neng. EL Nino/ENSO and climatic anomaly in the Autumn of China [J]. Journal of Tropical Meteorology, 2: 137-146(2003)

13. Smith T M, Reynolds R W. Improved Extended Reconstruction of SST (1854 - 1997)[J]. Journal of Climate,17(12): 2466-2477 (2004)

14. DING Yuguo, JIANG Zhihong. Generality of singular value decomposition in diagnostic analysis of meteorological filed [J]. Acta Meteorologica Sinica, 54(03): 365-372 (1996)

15. ZHANG Liping, KE Yiming, WANG Kangkang. Applications of singular value decomposition in the forecasting quantitatively fields $[\mathrm{J}]$. Journal of 
Tropical Meteorology, 20(04): 383-390(2004)

16. WANG Panxing, ZHOU Weican, WANG Xing, et al. SVD for meteorological vector fields with its applications [J]. Journal of Nanjing Institute of Meteorology, 20(02): 11-16 (1997)

17. DING Yihui. Advanced Synopic Meteorology [M]. Beijing: China Meteorological Press,: 745-766 (2005)

18. CHEN Lieting. The Temporal and Spatial Variations in Air-Sea Interaction over the Pacific Ocean [J]. Acta Meteorologica Sinica, 41(03): 296-304(1983)

19. LI Yaohui, LI Dongliang, ZHAO Qingyun, et al. Effect of ENSO on the Autumn Rainfall Anomaly in Northwest China [J]. Climatic and Environmental Research, 5(02): 205-213 (2000)

20. SUN Fenghua, YANG Suying, YUAN Jian. Climate change and extreme events over Northeast Part of China [M]. Beijing: China Meteorological Press, 8: 53 (2000)

21. ZHAO Zhenguo, LIAO Quansun. The relationship between the summer rainfall in China and the northern Pacific oscillation in Winter. Meteorological Monthly, 18(02): 11-16(1992)

22. HE Jinhaim, ZHOU Bing, WEN Ming, et al. Vertical Circulation Structure, Interannual VariationFeatures and Variation Mechanism of Western Pacific Subtropical High [J]. Advances in Atmospheric Sciences. 4: 497-510( 2001)

23. SHI Xinghe, Qin Ningsheng, MA Yuancang, et al. Analyses on Qinghai rainy Synoptic Precipitation in Summer of 1999 [J]. PLATEAU METEORLOGY, 21(02): 222-224(2002)

24. CHEN Xingfang, ZHAO Zhenguo. Research and Application of the Prediction of Raining Season in China [M]. Beijing: China Meteorological Press, 62-69, 21-25(2000)

25. JIA Xiaolong, ZHANG Peiqun, CHEN Lijuan, et al. Causality Analysis of Autumn Rainfall Anomalies in China in 2007 [J]. Meteorological Monthly, 34(04): 86-94(2008) 